\title{
The effect of chemotherapy on programmed cell death 1 / programmed cell death 1 ligand axis: some chemotherapeutical drugs may finally work through immune response
}

\author{
Min Luo ${ }^{1}$ and Liwu Fu ${ }^{1}$ \\ 1 State Key Laboratory of Oncology in South China, Collaborative Innovation Center for Cancer Medicine, Guangdong \\ Esophageal Cancer Institute, Sun Yat-Sen University Cancer Center, Guangzhou, China \\ Correspondence to: Liwu Fu, email: Fulw@mail.sysu.edu.cn \\ Keywords: programmed cell death 1, programmed cell death 1 ligand, chemotherapy, immunotherapy \\ Received: October 30, $2015 \quad$ Accepted: February 15, $2016 \quad$ Published: February 23, 2016
}

\section{ABSTRACT}

Most tumors are immunogenic which would trigger some immune response. Chemotherapy also has immune potentiating mechanisms of action. But it is unknown whether the immune response is associated with the efficacy of chemotherapy and the development of chemoresistance. Recently, there is a growing interest in immunotherapy, among which the co-inhibitory molecules, programmed cell death 1/programmed cell death 1 ligand (PD-1/PD-L1) leads to immune evasion. Since some reports showed that conventional chemotherapeutics can induce the expression of PD-L1, we try to summarize the effect of chemotherapy on PD-1/PD-L1 axis and some potential molecules relevant to PD-1/PD-L1 in chemoresistance in this review.

\section{INTRODUCTION}

Immunotherapy is a rising hope for cancer patients, utilizing the immune system to detect and eliminate foreign tumor antigens. But immune response is such a complex phenomenon involving clonal $\mathrm{T}$ cell selection, activation, proliferation and trafficking to antigen sites to deliver immune effector functions, that it's hard to hit the target in immunotherapy [1]. The process of $\mathrm{T}$ cell activation requires two major signals (Figure 1): the costimulatory signals and co-inhibitory signals [2]. The co-inhibitory signals could be a main actor in cancer progression through the inhibition of anti-cancer immune response [3]. One of the inhibitory signals is PD-1/PD-L1 axis. PD-1 is a member of the $\mathrm{B} 7$ receptor family and is inducibly expressed on activated $\mathrm{T}$ cell subsets including $\mathrm{T}$ follicular helper (Tfh) cells [5] and $\mathrm{T}$ regulatory (Treg) cells. It attenuates immune responses by negatively regulating $\mathrm{T}$ cell proliferation and function [4]. And the relationship between PD-L1 expression on tumor and/or immune cells and objective immune response has been reported [6-9].

Chemotherapy is a conventional treatment for cancer with different extent of cytotoxicity but has immune potentiating mechanisms of action [10]. Whether chemotherapy can stimulate immune response and finally kill tumors is unknown. Recent introduction of immune modulators, PD-1/PD-L1 adds much excitement to this field. It is reported that the expression rate of PD-L1 in human malignant tumors varies from $19 \%$ to $92 \%$ [11] and the expression of PD-L1 is positively correlated with tumor progression [12-15]. PD-L1 overexpression predicted better pathological response to chemotherapy, independently of histo-clinical variables and predictive gene expression signatures [16]. Zhang et al. [18] demonstrated that paclitaxel, etoposide and 5-fluorouracil were able to induce PD-L1 surface expression in human breast cancer cells and increase PD-L1-mediated $\mathrm{T}$ cell apoptosis, revealing a potential link between chemotherapy and cancer immunoresistance. PD-L1 is expressed by cancer cells, the exact mechanism of how the chemotherapeutic drugs work on tumor microenvironment especially PD-1/PD-L1 axis and how this PD-1/PD-L1 axis induces chemoresistance is not clear. Herein, in this review, we try to summarize the relationships between chemotherapy and immune response through PD-1/PDL1 axis.

\section{DIFFERENT CHEMOTHERAPEUTIC AGENTS HAVE DIFFERENT EFFECTS ON IMMUNE SYSTEM}

Accumulating evidences suggest that conventional therapeutic regimens as well as targeted anticancer agents, 
originate (at least in part) from their ability to elicit a novel or reinstate a pre-existing tumor-specific immune response $[19,20]$. One of the mechanisms is that chemotherapy can provoke the immune system to recognize and destroy malignant cells called immunogenic cell death (ICD) [21]. Several common chemotherapeutics share the ability to trigger ICD, (e.g., doxorubicin, epirubicin, idarubicin, mitoxantrone, bleomycin, bortezomib, cyclophosphamide and oxaliplatin) $[21,22]$ as well as some anticancer agents that are still under preclinical or clinical development (e.g., some microtubular inhibitors of the epothilone family) [21, 22]. Among the various chemotherapeutic drugs that have been tested on mice, anthracyclines are the only agents that provide enhanced immunity to further battle with tumor cells [23]. Recent data indicate that cyclophosphamide at high doses have the immunosuppressive properties, while metronomic cyclophosphamide regimens exert contrary immunostimulatory effects [20] by selectively depleting or inhibiting Tregs [24]. Such immunostimulatory properties seem to, at least in part, contribute to the therapeutic success by cyclophosphamide as a conventional anticancer agent [25]. Importantly, many clinical studies demonstrated that metronomic cyclophosphamide led to improved $\mathrm{T}$ cell effector functions [19, 26]. Cancer cells evade immune recognition via down-regulating human leukocyte antigen (HLA) Class I expression, allowing their escape from immune surveillance and destruction [27]. While in ovarian cancer cells, low-dose epothilone B, taxol and vinblastine greatly increased expression of HLA Class I and HLA-A2 molecules, and low-dose epothilone B treatment markedly increased the expression of interferon- $\alpha$, IL-1 $\beta$, IL-12 and IL-6 [27]. In the inflammatory microenvironment, interferon- $\gamma$ (IFN- $\gamma$ ) and other inflammatory cytokines, secreted by antitumor Th1 cells or macrophages, may upregulate PD-L1 expression in response to immune-mediated attack [6], to decrease the cytotoxic local immune response. Some anti-tumor drugs can promote the cytokines (IFN, IL-6) release to upregulate PD-L1 constitutively or in response to inflammation [6]. PD-L1 is upregulated in cancerous cells in vitro by immune cytokines that are critical for $\mathrm{T}$ cell functioning, such as IFN- $\gamma$ [28], which may even positively feedback to enhance immune tolerance in vivo (Figure 2). Collectively, these studies indicate that different chemotherapeutic agents have different effects on immune system.

\section{CHEMOTHERAPY ALTERS THE EXPRESSION OF PD-1/PD-L1}

Besides inducing ICD, oxaliplatin are reported to inhibit the expression of programmed death ligand 2 (PD-L2), thereby limiting immunosuppression by both dendritic cells (DCs) and tumor cells [29]. Treatment with paclitaxel and etoposide upregulated PD-L1 expression

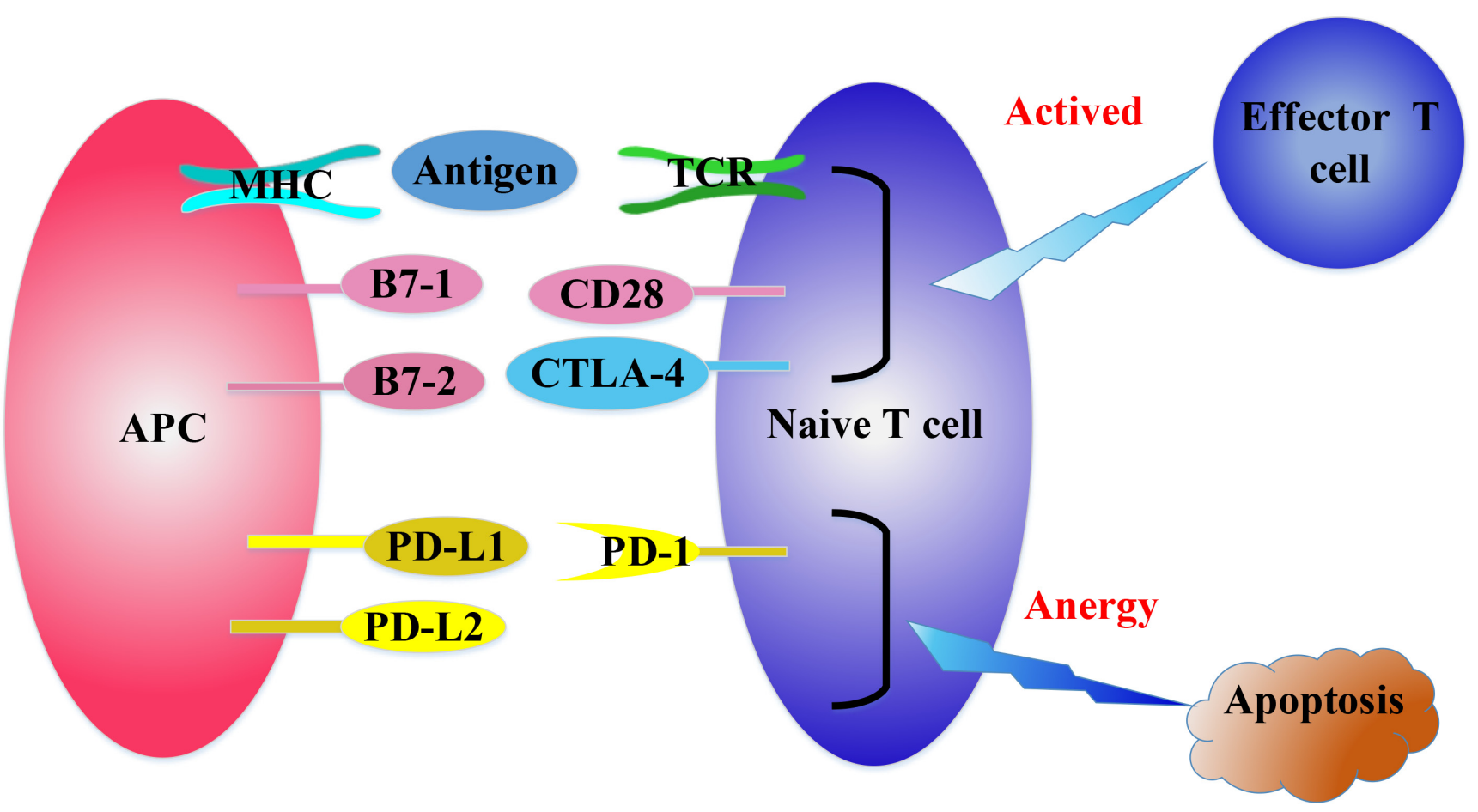

Figure 1: The regulation of $\mathbf{T}$ cell activation. $T$ cell receptor (TCR) recognizes the tumor antigens in the context of major histocompatibility complex (MHC) expressed on professional antigen presenting cells (APCs). Then APCs deliver a second signal by positive co-stimulatory molecules CD28/B7-1/B7-2 to fully activate naive T cells. CTLA-4 can bind with B7-1/B7-2 competitively to inhibit the activation of CD28/B7-1/B7-2, resulting in inactivation of T cells. PD-1 binds with its ligands, PD-L1 and PD-L2 to attenuate lymphocyte activation. 
in breast cancer cells, resulting in co-inhibitory signals activation [18]. Yang et al. [30] observed an increase of PD-L1 and PD-1 antigen expression in leukemia cells with decitabine treatment, and both PD-L1 and PD-1 expression were increased in a concentration dependent manner. QIN et al. [31] demonstrated that when the cisplatin concentration is less than $\mathrm{IC}_{50}$, cisplatin could upregulate PD-L1 expression in hepatoma H22 cells. Meanwhile, cisplatin could activate the phosphorylation of ERK1/2, and that cisplatin-induced PD-L1 expression is dependent of ERK1/2 phosphorylation [31]. Oki et al. [32] observed a suppression of PD-1 expression after treatment with panobinostat (a histone deacetylase). It suggests that panobinostat may exert anti-tumor activity by decreasing PD-1 expression in normal lymphocytes, stimulating the immune reaction against lymphoma [32]. PD-L1 and its signaling pathway appear to be a potential therapeutic target for cancer. Interestingly, a recent research demonstrated that PD-L1 expression had the capability to change over time with anti-PD-L1 antibody therapy [33]. Therefore, its expression status of a specific tumor tissue may not reflect the present immunologic phenotype of tumor. Doxorubicin is reported to downregulate PD-L1 expression on cell surface, while upregulate its nuclear expression in breast cancer cells [34]. A decrease in PD-L1 expression on cell surface is expected to increase the immunogenicity of the cancer cells, and its translocation to the nucleus is likely to be responsible for the anti-apoptotic impact of anthracyclines on cancer cells and their microenvironment [34]. The translocation of PD-L1 from the cell surface to the nucleus induced by doxorubicin occurs concurrently with AKT phosphorylation, but the PI3K/AKT pathway is not involved in this process [34], which indicates that the PDL1 re-distribution from the cell surface to the nucleus is regulated by two signaling, including an AKT-dependent pathway (dominant in the nucleus) and an unknown AKTindependent pathway (dominant on the cell surface). Moreover, doxorubicin combined with PD-L1 knockdown has been shown to enhance apoptosis [34]. This indicates that its nuclear localization can enhance the anti-apoptotic function, which may link with the apoptotic machinery of the cell. As for the molecular mechanism of how to regulate PD-L1 expression has yet to be understood, but several researchers described the presence of proinflammation and inflammation may take part in it [35]. Further studies are needed to explore the mechanism of chemotherapy-induced PD-L1 expression in cancer cells.

\section{SOME SIGNAL MOLECULES ASSOCIATED WITH PD-L1 EXPRESSION}

Zhang et al. [18] showed that chemotherapeutic agents potentiated IFN- $\gamma$-induced PD-L1 expression in human breast cancer cells. All the chemotherapeutic

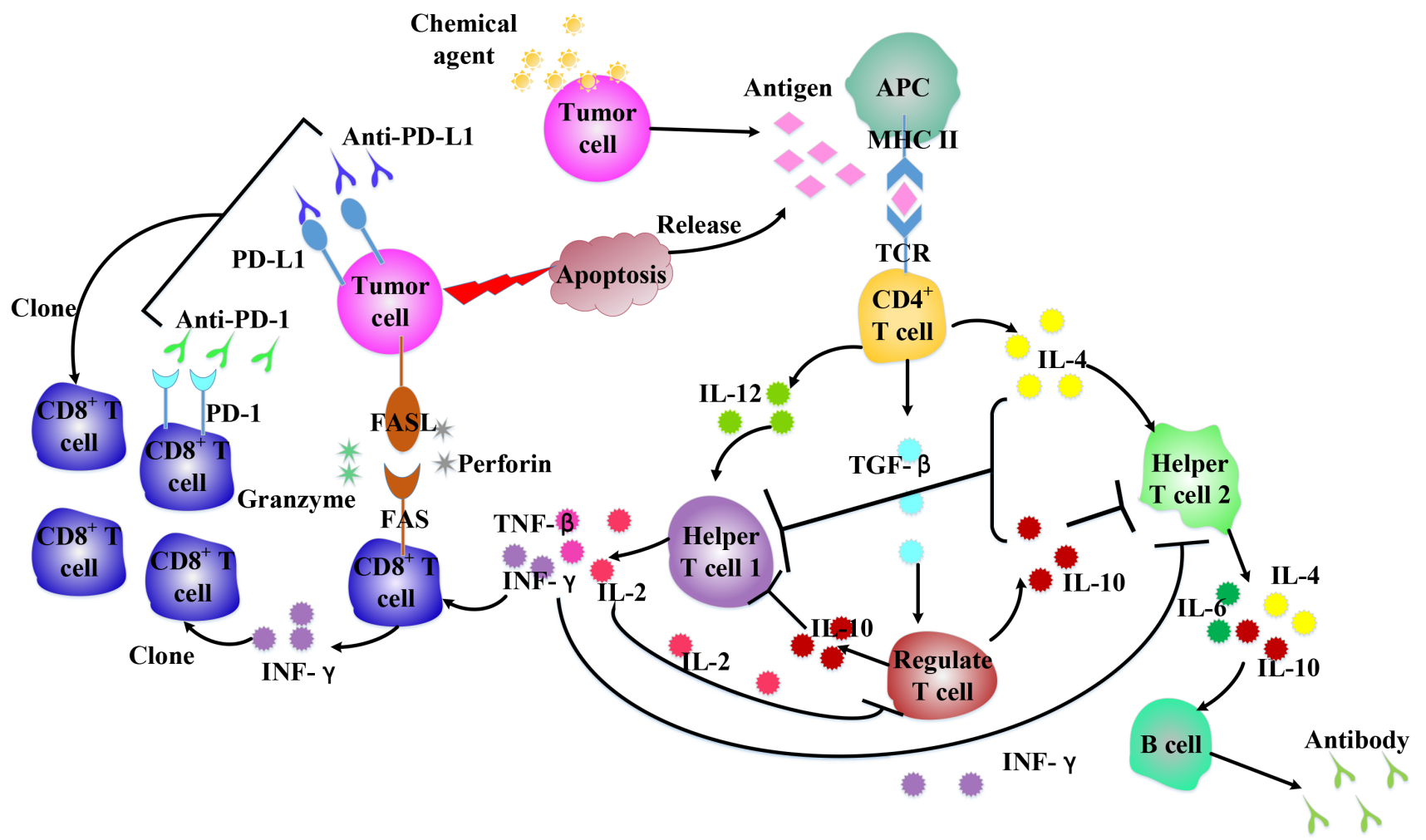

Figure 2: Chemotherapeutic agents influence cytokines network in antitumor immune system. Different chemical agents work on immune cells, leading to various cytokines released, which can affect the immune cells populations to enhance/attenuate antitumor response. 
agents tested in the study had similar effects on PD-L1 surface expression in breast cancer cells [18], suggesting that they may act through a common pathway (Figure 3). IFN- $\gamma$ enhances cancer immunoresistance by upregulating the expression of PD-L1 and PKD2 (Polycystic Kidney Disease Gene 2) in human oral squamous carcinoma cells in both time and dose dependent manner [36]. PKD2 knockdown with shRNA / siRNA or PKD chemical inhibitor resulted in IFN- $\gamma$ production, then downregulated the expression of PD-L1 [36]. And the activation of PKD2 can stimulate the expression of $\mathrm{P}$ glycoprotein $(\mathrm{P}-\mathrm{gp})$ [37]. Inhibition of PKD2 activation could significantly inhibit the expression of P-gp and decrease multiple drug resistance (MDR) in human breast cancer cells [38], indicating that PKD2 may be an important target for tumor biotherapy and MDR reversal. Signaling through key proliferative pathways, like MEK/ERK and PI3K/ AKT can also increase PD-L1 expression in malignant glioma, prostate and breast carcinoma $[39,40]$. Berthon et al. [41] confirmed that blocking MEK inhibited PDL1 transcription in the AML cell lines THP-1 and U937, suggesting that MEK is an important regulator of PD-L1 expression in leukemic cells. Non-small-cell lung cancer
(NSCLC) cell lines bearing EGFR, KRAS, BRAF, ALK or RET mutations were found with high level of PD-L1 expression, and this may be correlated with high levels of $\mathrm{PI} 3 \mathrm{~K} / \mathrm{AKT} / \mathrm{mTOR}$ pathway activation. PD-L1 expression markedly increased in a subset of patients after acquiring resistance to gefitinib in EGFR-mutant NSCLC [42]. Loss of the phosphatase and tensin homolog (PTEN) through genetic deletions or mutations accelerates PD-L1 expression in tumors [43]. Crane et al. [40] demonstrated that PI3K activation caused by loss of PTEN function enhanced PD-L1 protein level expression in breast cancer cell lines. Parsa et al. [43] found an increase of the posttranscriptional PD-L1 expression in other types of PTEN loss cancers with the activation of the PI3K pathway. The transformed cells can also utilize PI3K pathway to evade the immune system by mimicking immune cells [44], developing resistance to $\mathrm{T}$ cell induced apoptosis [45], secreting immunosuppressive cytokines [46], enhancing the immunosuppressive potential of Treg cells [47] or emulating immune cell chemotactic responses [48]. Inhibition of PI3K or its downstream signaling molecule AKT decreased PD-L1 expression in tumor cells and increased cytotoxic T cells-induced killing [43]. Therefore,

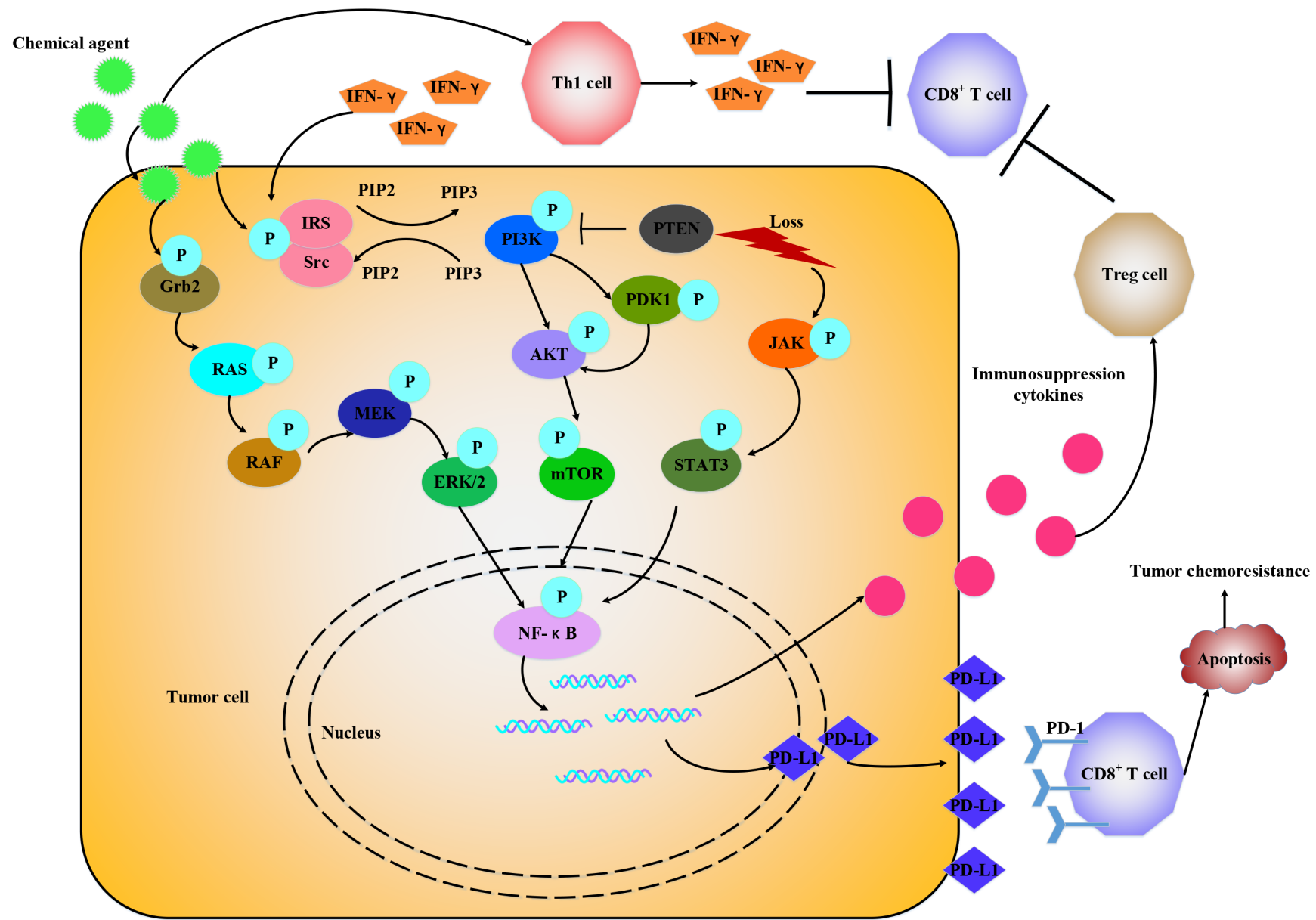

Figure 3: Chemotherapeutic agents promote PD-1/PD-L1 expression through various signals. Chemotherapeutic agents via IFN- $\gamma$-dependent and IFN- $\gamma$-independent way to upregulate PD-L1 expression by activating different signals, like RAS/RAF, PI3K/ AKT, JAK/STAT3 and release some immune suppression cytokines to attenuate antitumor immune response. 
targeting PD-1/PD-L1 interaction may be enhanced when combined with PI3K inhibitors. The complex interaction between PI3K signal and anti-tumor immune response needs further studies. It also represents a promising avenue to best exploit the anti-tumor effects of clinical PI3K inhibitors. Toso et al. [49] showed that in PTEN-null senescent tumors, activation of the JAK2/STAT3 pathway induced an immunosuppressive tumor microenvironment that contributed to tumor growth and chemoresistance. Inhibition of the JAK2/STAT3 pathway in PTEN-deficient prostate tumors led to senescence-associated cytokine network reprogrammed, and improved the efficacy of docetaxel-induced senescence by triggering a strong antitumor immune response. Soliman et al. [37] reported that high PD-L1 basal cell lines had lower expression of IRF2BP2 (interferon regulatory factor 2 binding protein 2) and higher STAT1 levels compared to those with low PD-
L1 expression. All findings above suggest that regulation of PD-L1 expression varies widely among cell types and drugs targeting signal transduction pathways might have different immunological effects in different tumors.

\section{PD-1/PD-L1 IN CHEMORESISTANCE}

A research [41] showed that in five out of nine patients with AML, spontaneous PD-L1 expression increased when they relapsed. Lower expression of PD-L1 was positive correlated with a tendency to longer survival [30]. Jennifer et al. [50] found that in progressing prostate cancer patients, more PD-L1/2 $2^{+}$DCs led to poorer response to Enzalutamide (ENZ) treatment and shorter treatment duration. They also observed that circulating PD-L1/2 DCs significantly increased in mice bearing Enzalutamide resistant (ENZR) tumors compared to castration resistant

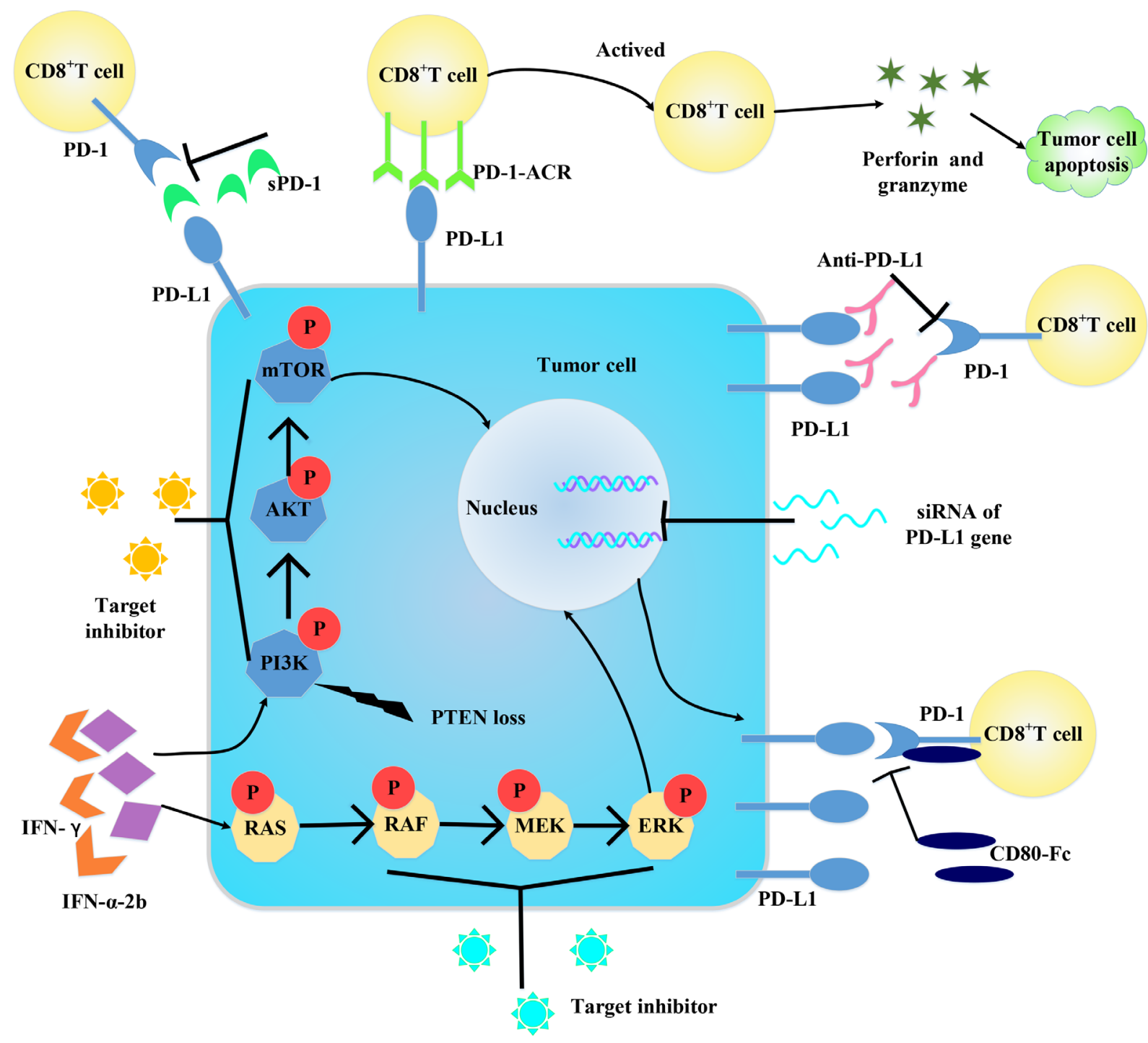

Figure 4: Some strategies for blocking PD-1/PD-L1 axis. Targeting PD-1/PD-L1 and its downstream molecules can block the axis to activate. And siRNA can downregulate PD-L1 expression from gene level. Changing the construct of PD-1 can convert it into a co-stimulatory molecule to enhance immune response. Target IFN- $\gamma$ can decrease IFN- $\gamma$-induced PD-L1 expression. Administration of molecules bind with PD-1/PD-L1 can interfere the binding between PD-1 and PD-L1, thus inactive the PD-1/PD-L1 axis. 
Table 1: Some anti-PD-1/PD-L1 antibodies in clinical trials

\begin{tabular}{|l|l|l|l|l|l|}
\hline Agents & Alias & Target & Clinical trial & Application & Details \\
\hline Nilvolumab & $\begin{array}{l}\text { BMS-936559, } \\
\text { MDX-1106 }\end{array}$ & PD-1 & $\begin{array}{l}\text { Approved by } \\
\text { FDA }\end{array}$ & $\begin{array}{l}\text { Melanoma, renal cell } \\
\text { carcinoma and non- } \\
\text { small cell lung cancer }\end{array}$ & $/$ \\
\hline Pembrolizumab & $\begin{array}{l}\text { MK-3475, } \\
\text { Lambrolizumab }\end{array}$ & PD-1 & $\begin{array}{l}\text { Approved by } \\
\text { FDA }\end{array}$ & Advanced melanoma & $/$ \\
\hline Pidilizumab [66] & CT-011 & PD-1 & Phase II & $\begin{array}{l}\text { Hematological } \\
\text { malignant tumor }\end{array}$ & $\begin{array}{l}\text { 72 patients enrolled, PFS: 0.72 (90\% } \\
\text { C.60 to 0.82), toxicity: 23/72 } \\
\text { (31.94\%) blood and lymphatic system } \\
\text { disorders }\end{array}$ \\
\hline MPDL3280A & Atezolizumab & PD-L1 & Phase III & $\begin{array}{l}\text { Non-small cell lung } \\
\text { cancer, }\end{array}$ & Ongoing (NCT01846416) \\
\hline MEDI4736 & Durvalumab & PD-L1 & Phase II & $\begin{array}{l}\text { Non-small cell lung } \\
\text { cancer }\end{array}$ & Ongoing (NCT02087423) \\
\hline Avelumab & MSB0010718C & PD-L1 & Phase II & M-Merkel cell cancer & Ongoing (NCT02155647) \\
\hline
\end{tabular}

prostate cancer, and ENZR tumors expressed significantly increasing levels of tumor-intrinsic PD-L1. Altogether, it suggests that there are high expressions of PD-1/PDL1 pathway molecules in peripheral blood immune cells in patients with ENZR castration resistant prostate cancer (CRPC). Another research [51] showed that drugresistant osteosarcoma cell line KHOSR2 and virallyderived osteoblast cell line hFOB had high (3-log) PDL1 gene expression, and osteosarcoma cell line $\mathrm{SaOS}$ and breast cancer cell line MCF-7 had low $(<1-\log )$ expression. Each osteosarcoma cell line generally has various PD-L1 expression, ranged from low to high PD-L1 expression, with slightly higher expression from drug-resistant variants (KHOSR2 and U-2OSTR) than their parental cell lines (KHOS and U-2OS) [51]. Thus, PD-1/PD-L1 blockade has the potential to overcome resistance, and the combination therapy of chemotherapy and PD-1/PD-L1 blockade has the potent synergistic effects to enhance antitumor immunity. Schatton et al. [52] identified tumorigenic human $\mathrm{ABCB}^{+}$MMICs (a novel type of cancer stem cells, malignant melanomainitiating cells), expressing chemoresistance determinant ABCB5 preferentially expressed PD-1 and B7-2, but with downregulated expression of PD-L1 compared to ABCB5- cells [53]. The relationship between PD-L1 and chemoresistance determinant $\mathrm{ABCB} 5$ is worthy to further study. The PD-L1 $1^{\text {high }}$ cells were demonstrated significantly resistant to CDDP (compound Danshen dripping pills) and TXL (Tongxinluo) compared with the PD-L $1^{\text {low }}$ cells [54]. As for the mechanism of how PD-L1 increases the chemoresistance, Yu Fujita et al. [54] found that a miR197 mimic can sensitize PD-L1 ${ }^{\text {high }}$ drug-resistant cells to chemotherapy, indicating that the biological interaction between PD-L1 and chemoresistance occurs through the microRNA regulatory cascade. The overexpression of miR-197 induced decreased expression of PD-L1 in NSCLC cells [54]. The miR-197/CKS1B/STAT3 axis can drive tumor PD-L1 expression as a biomarker of this cascade, and miR-197 replacement therapy may be a potential treatment strategy for chemoresistant NSCLC [54].

\section{STRATEGIESFORBLOCKINGPD-1/PD-L1 AXIS IN CHEMORESISTANCE}

With its profound immunosuppressive effect, PD-1/ PD-L1 axis has been the focus of several recent studies aiming at neutralizing its detrimental effects on $\mathrm{T}$ cell anti-tumor response (Figure 4). There are now multiple agents targeting the PD-1/PD-L1 at different stages of clinical development [9, 55-57] (Table 1). PD-1 and PD-L1 antibodies have shown considerable clinical efficacy and durability across a range of malignancy subtypes, including melanoma and lung cancer $[9,58]$ and most recently in refractory Hodgkin's disease [59], and quite a lot of phase II studies are ongoing in prospect (NCT02572167, NCT02181738, NCT02327078). It decreases the metastatic risk and improves the therapeutic response when associated with immunogenic anticancer chemotherapy such as doxorubicin [60,61]. As some signal molecules are reported to upregulate PDL1 expression, the target inhibitors may be a potential treatment (Figure 4). Other immune modulatory agents, like IFN- $\alpha-2 b$, are going on clinical trials combined with different anti-PD-1 and anti-PD-L1 antibodies (NCT01943422, NCT01608594). Nivolumab (NCT02464657, NCT01658878), pembrolizumab (NCT02551432), MEDI4736 (NCT02027961), and MPDL3280A (NCT01633970, NCT02525757, NCT02409355) are being evaluated in combination with chemotherapies, tyrosine kinase inhibitors, or other targeted therapies. Recently, Tang et al. [62] converted PD-1 to a $\mathrm{T}$ cell co-stimulatory receptor by exchanging its trans-membrane and cytoplasmic tail with $\mathrm{CD} 28$ and 4-1BB signaling domains (PD-1-CD28-4-1BB, PD-1ACR), which retained the ability to bind PD-L1, but resulting in $\mathrm{T}$ cell activation as evidenced by the elevated activity of PI3K/AKT, the augmentation of cytokine 
secretion and the increased proliferative capacity. Samuel et al. [63] reported that CD80-Fc (the fragment of CD80 $\mathrm{IgG}$ ) is more effective in preventing PD-1/PD-L1-induced suppression and restoring $\mathrm{T}$ cell activation compared to treatment with $\mathrm{mAb}$ to either PD-1 or PD-L1. Soluble PD-1 (sPD-1) is an efficient way to bind PD-L1 and to block PD-1/PD-L1 interactions, in conjunction with a two-domain molecule of fibronectin (CH50) in inhibiting tumor invasion and growth in hepatoma [64]. A study [65] showed that using short-hairpin double-stranded silencing RNA (siRNA) to restrain the expression of PD-1 on the cell surface of tumor-specific $\mathrm{T}$ cells, improved immune responses. In addition, it remains to be seen whether ICD inducers (e.g., doxorubicin, epirubicin, etc.) may be advantageously combined with non-immunogenic conventional chemotherapeutics, targeted anticancer agents and/or immunostimulatory strategies. It is crucial for the discovery of next-generation chemotherapeutics, i.e., molecules that simultaneously hit cancer cells while exerting potent immunostimulatory effect. These agents may be particularly relevant for the development of combinatorial chemotherapeutic regimens that actively engage the host immune system against malignant cells.

\section{SUMMARY}

A better understanding of how chemotherapy affects the anti-tumor immunity and causes chemoresistance is crucial. But it is still unknown how the signaling events regulate the expression of these molecules in resistant cancer cells. Blockade of the PD-1/PD-L1 pathway is a new, promising immunotherapy for cancer. Strategic combination of immunotherapy and chemotherapy can effectively change the overall tumor microenvironment, as well as immune tolerance and immune suppression, which can maintain effective and durable anti-tumor immune response.

\section{ACKNOWLEDGMENTS}

We thank Xiao-Na Fang and De-Lan Li for revising the manuscript for better reading.

\section{CONFLICTS OF INTEREST}

Authors have no relevant, potential conflicts of interest to declare.

\section{FUNDING}

The research was supported by Major State Basic Research Development Program of China (973 Program, No.2012CB967000) and Natural scientific Foundation of China (No. 81473233).

\section{REFERENCES}

1. Pardoll DM. The blockade of immune checkpoints in cancer immunotherapy. Nat Rev Cancer. 2012; 12:252-264.

2. Hamel KM, Cao Y, Wang Y, Rodeghero R, Kobezda T, Chen L and Finnegan A. B7-H1 expression on non-B and non- $\mathrm{T}$ cells promotes distinct effects on $\mathrm{T}$ - and B-cell responses in autoimmune arthritis. Eur J Immunol. 2010; 40:3117-3127.

3. Reiss KA, Forde PM and Brahmer JR. Harnessing the power of the immune system via blockade of PD-1 and PDL1: a promising new anticancer strategy. Immunotherapy. 2014; 6:459-475.

4. Park HJ, Kusnadi A, Lee EJ, Kim WW, Cho BC, Lee IJ, Seong $\mathrm{J}$ and Ha SJ. Tumor-infiltrating regulatory $\mathrm{T}$ cells delineated by upregulation of PD-1 and inhibitory receptors. Cell Immunol. 2012; 278:76-83.

5. Crotty S. Follicular helper CD4 T cells (TFH). Annu Rev Immunol. 2011; 29:621-663.

6. Taube JM, Klein A, Brahmer JR, Xu H, Pan X, Kim JH, Chen L, Pardoll DM, Topalian SL and Anders RA. Association of PD-1, PD-1 ligands, and other features of the tumor immune microenvironment with response to antiPD-1 therapy. Clin Cancer Res. 2014; 20:5064-5074.

7. Tumeh PC, Harview CL, Yearley JH, Shintaku IP, Taylor EJ, Robert L, Chmielowski B, Spasic M, Henry G, Ciobanu V, West AN, Carmona M, Kivork C, Seja E, Cherry G, Gutierrez AJ, et al. PD-1 blockade induces responses by inhibiting adaptive immune resistance. Nature. 2014; 515:568-571.

8. Herbst RS, Soria JC, Kowanetz M, Fine GD, Hamid O, Gordon MS, Sosman JA, McDermott DF, Powderly JD, Gettinger SN, Kohrt HE, Horn L, Lawrence DP, Rost S, Leabman M, Xiao Y, et al. Predictive correlates of response to the anti-PD-L1 antibody MPDL3280A in cancer patients. Nature. 2014; 515:563-567.

9. Topalian SL, Hodi FS, Brahmer JR, Gettinger SN, Smith DC, McDermott DF, Powderly JD, Carvajal RD, Sosman JA, Atkins MB, Leming PD, Spigel DR, Antonia SJ, Horn L, Drake CG, Pardoll DM, et al. Safety, activity, and immune correlates of anti-PD-1 antibody in cancer. N Engl J Med. 2012; 366:2443-2454.

10. Zitvogel L, Apetoh L, Ghiringhelli F, Andre F, Tesniere A and Kroemer G. The anticancer immune response: indispensable for therapeutic success? J Clin Invest. 2008; 118:1991-2001.

11. Sznol $\mathrm{M}$ and Chen L. Antagonist antibodies to PD-1 and B7-H1 (PD-L1) in the treatment of advanced human cancer-response. Clin Cancer Res. 2013; 19:5542.

12. Kang MJ, Kim KM, Bae JS, Park HS, Lee H, Chung MJ, Moon WS, Lee DG and Jang KY. Tumor-infiltrating PD1Positive Lymphocytes and FoxP3-Positive Regulatory T Cells Predict Distant Metastatic Relapse and Survival of Clear Cell Renal Cell Carcinoma. Transl Oncol. 2013; 
6:282-289.

13. French JD, Kotnis GR, Said S, Raeburn CD, McIntyre RC, Jr., Klopper JP and Haugen BR. Programmed death-1+ T cells and regulatory $\mathrm{T}$ cells are enriched in tumor-involved lymph nodes and associated with aggressive features in papillary thyroid cancer. J Clin Endocrinol Metab. 2012; 97:E934-943.

14. Shi F, Shi M, Zeng Z, Qi RZ, Liu ZW, Zhang JY, Yang YP, Tien P and Wang FS. PD-1 and PD-L1 upregulation promotes $\mathrm{CD} 8(+)$ T-cell apoptosis and postoperative recurrence in hepatocellular carcinoma patients. Int $\mathrm{J}$ Cancer. 2011; 128:887-896.

15. Richendollar BG, Pohlman B, Elson P and Hsi ED. Follicular programmed death 1-positive lymphocytes in the tumor microenvironment are an independent prognostic factor in follicular lymphoma. Hum Pathol. 2011; 42:552557.

16. Bertucci F, Finetti P, Colpaert C, Mamessier E, Parizel M, Dirix L, Viens P, Birnbaum D and van Laere S. PDL1 expression in inflammatory breast cancer is frequent and predicts for the pathological response to chemotherapy. Oncotarget. 2015; 6:13506-13519. doi: 10.18632/ oncotarget.3642.

17. Sabatier R, Finetti P, Mamessier E, Adelaide J, Chaffanet M, Ali HR, Viens P, Caldas C, Birnbaum D and Bertucci F. Prognostic and predictive value of PDL1 expression in breast cancer. Oncotarget. 2015; 6:5449-5464. doi: 10.18632/oncotarget.3216.

18. Zhang $\mathrm{P}, \mathrm{Su} \mathrm{DM}$, Liang $\mathrm{M}$ and Fu J. Chemopreventive agents induce programmed death-1-ligand 1 (PD-L1) surface expression in breast cancer cells and promote PDL1-mediated T cell apoptosis. Molecular immunology. 2008; 45:1470-1476.

19. Ghiringhelli F, Menard C, Puig PE, Ladoire S, Roux S, Martin F, Solary E, Le Cesne A, Zitvogel L and Chauffert B. Metronomic cyclophosphamide regimen selectively depletes $\mathrm{CD} 4+\mathrm{CD} 25+$ regulatory $\mathrm{T}$ cells and restores $\mathrm{T}$ and NK effector functions in end stage cancer patients. Cancer immunology, immunotherapy. 2007; 56:641-648.

20. Galluzzi L, Senovilla L, Zitvogel L and Kroemer G. The secret ally: immunostimulation by anticancer drugs. Nature reviews Drug discovery. 2012; 11:215-233.

21. Pol J, Vacchelli E, Aranda F, Castoldi F, Eggermont A, Cremer I, Sautes-Fridman C, Fucikova J, Galon J, Spisek R, Tartour E, Zitvogel L, Kroemer G and Galluzzi L. Trial Watch: Immunogenic cell death inducers for anticancer chemotherapy. Oncoimmunology. 2015; 4:e1008866.

22. Vacchelli E, Aranda F, Eggermont A, Galon J, SautesFridman C, Cremer I, Zitvogel L, Kroemer G and Galluzzi L. Trial Watch: Chemotherapy with immunogenic cell death inducers. Oncoimmunology. 2014; 3:e27878.

23. Casares N, Pequignot MO, Tesniere A, Ghiringhelli F, Roux S, Chaput N, Schmitt E, Hamai A, Hervas-Stubbs S, Obeid M, Coutant F, Metivier D, Pichard E, Aucouturier
P, Pierron G, Garrido C, et al. Caspase-dependent immunogenicity of doxorubicin-induced tumor cell death. The Journal of experimental medicine. 2005; 202:16911701.

24. Nakahara T, Uchi H, Lesokhin AM, Avogadri F, Rizzuto GA, Hirschhorn-Cymerman D, Panageas KS, Merghoub T, Wolchok JD and Houghton AN. Cyclophosphamide enhances immunity by modulating the balance of dendritic cell subsets in lymphoid organs. Blood. 2010; 115:43844392.

25. Emadi A, Jones RJ and Brodsky RA. Cyclophosphamide and cancer: golden anniversary. Nature reviews Clinical oncology. 2009; 6:638-647.

26. Greten TF, Ormandy LA, Fikuart A, Hochst B, Henschen S, Horning M, Manns MP and Korangy F. Low-dose cyclophosphamide treatment impairs regulatory $\mathrm{T}$ cells and unmasks AFP-specific CD4+ T-cell responses in patients with advanced HCC. Journal of immunotherapy. 2010; 33:211-218.

27. Pellicciotta I, Yang CP, Goldberg GL and Shahabi S. Epothilone B enhances Class I HLA and HLA-A2 surface molecule expression in ovarian cancer cells. Gynecologic oncology. 2011; 122:625-631.

28. Taube JM, Anders RA, Young GD, Xu H, Sharma R, McMiller TL, Chen S, Klein AP, Pardoll DM, Topalian SL and Chen L. Colocalization of inflammatory response with B7-h1 expression in human melanocytic lesions supports an adaptive resistance mechanism of immune escape. Sci Transl Med. 2012; 4:127ra137.

29. Lesterhuis WJ, Punt CJ, Hato SV, Eleveld-Trancikova D, Jansen BJ, Nierkens S, Schreibelt G, de Boer A, Van Herpen CM, Kaanders JH, van Krieken JH, Adema GJ, Figdor CG and de Vries IJ. Platinum-based drugs disrupt STAT6-mediated suppression of immune responses against cancer in humans and mice. The Journal of clinical investigation. 2011; 121:3100-3108.

30. Yang H, Bueso-Ramos C, DiNardo C, Estecio MR, Davanlou M, Geng QR, Fang Z, Nguyen M, Pierce S, Wei Y, Parmar S, Cortes J, Kantarjian H and Garcia-Manero G. Expression of PD-L1, PD-L2, PD-1 and CTLA4 in myelodysplastic syndromes is enhanced by treatment with hypomethylating agents. Leukemia. 2014; 28:1280-1288.

31. Qin X, Liu C, Zhou Y and Wang G. Cisplatin induces programmed death-1-ligand 1(PD-L1) over-expression in hepatoma H22 cells via Erk /MAPK signaling pathway. Cell Mol Biol (Noisy-le-grand). 2010; 56 Suppl:OL1366-1372.

32. Oki Y, Buglio D, Zhang J, Ying Y, Zhou S, Sureda A, Ben-Yehuda D, Zinzani PL, Prince HM, Harrison SJ, Kirschbaum M, Johnston PB, Shen A, von Tresckow B and Younes A. Immune regulatory effects of panobinostat in patients with Hodgkin lymphoma through modulation of serum cytokine levels and T-cell PD1 expression. Blood Cancer J. 2014; 4:e236.

33. Tanaka OM, Araujo EA, Oliver DR and Behrents RG. A finite element analysis of the maxillary first molar PDL 
with maxillary protraction in a mixed dentition Class III malocclusion. Orthodontics \& craniofacial research. 2015.

34. Ghebeh H, Lehe C, Barhoush E, Al-Romaih K, Tulbah A, Al-Alwan M, Hendrayani SF, Manogaran P, Alaiya A, Al-Tweigeri $\mathrm{T}$, Aboussekhra $\mathrm{A}$ and Dermime $\mathrm{S}$. Doxorubicin downregulates cell surface B7-H1 expression and upregulates its nuclear expression in breast cancer cells: role of B7-H1 as an anti-apoptotic molecule. Breast Cancer Res. 2010; 12:R48.

35. Zhao Q, Xiao X, Wu Y, Wei Y, Zhu LY, Zhou J and Kuang DM. Interleukin-17-educated monocytes suppress cytotoxic T-cell function through B7-H1 in hepatocellular carcinoma patients. Eur J Immunol. 2011; 41:2314-2322.

36. Chen J, Feng Y, Lu L, Wang H, Dai L, Li Y and Zhang P. Interferon-gamma-induced PD-L1 surface expression on human oral squamous carcinoma via PKD2 signal pathway. Immunobiology. 2012; 217:385-393.

37. Soliman H, Khalil F and Antonia S. PD-L1 expression is increased in a subset of basal type breast cancer cells. PloS one. 2014; 9:e88557.

38. Chen J, Lu L, Feng Y, Wang H, Dai L, Li Y and Zhang P. PKD2 mediates multi-drug resistance in breast cancer cells through modulation of P-glycoprotein expression. Cancer letters. 2011; 300:48-56.

39. Hasan A, Ghebeh H, Lehe C, Ahmad R and Dermime S. Therapeutic targeting of B7-H1 in breast cancer. Expert opinion on therapeutic targets. 2011; 15:1211-1225.

40. Crane CA, Panner A, Murray JC, Wilson SP, Xu H, Chen L, Simko JP, Waldman FM, Pieper RO and Parsa AT. PI(3) kinase is associated with a mechanism of immunoresistance in breast and prostate cancer. Oncogene. 2009; 28:306-312.

41. Berthon C, Driss V, Liu J, Kuranda K, Leleu X, Jouy N, Hetuin D and Quesnel B. In acute myeloid leukemia, B7H1 (PD-L1) protection of blasts from cytotoxic $\mathrm{T}$ cells is induced by TLR ligands and interferon-gamma and can be reversed using MEK inhibitors. Cancer Immunol Immunother. 2010; 59:1839-1849.

42. Han JJ, Kim DW, Koh J, Keam B, Kim TM, Jeon YK, Lee $\mathrm{SH}$, Chung DH and Heo DS. Change in PD-L1 Expression After Acquiring Resistance to Gefitinib in EGFR-Mutant Non-Small-Cell Lung Cancer. Clinical lung cancer. 2015.

43. Parsa AT, Waldron JS, Panner A, Crane CA, Parney IF, Barry JJ, Cachola KE, Murray JC, Tihan T, Jensen MC, Mischel PS, Stokoe D and Pieper RO. Loss of tumor suppressor PTEN function increases B7-H1 expression and immunoresistance in glioma. Nat Med. 2007; 13:84-88.

44. Hemon P, Jean-Louis F, Ramgolam K, Brignone C, Viguier M, Bachelez H, Triebel F, Charron D, Aoudjit F, Al-Daccak $\mathrm{R}$ and Michel L. MHC class II engagement by its ligand LAG-3 (CD223) contributes to melanoma resistance to apoptosis. Journal of immunology. 2011; 186:5173-5183.

45. Noh KH, Kang TH, Kim JH, Pai SI, Lin KY, Hung CF, Wu TC and Kim TW. Activation of Akt as a mechanism for tumor immune evasion. Molecular therapy. 2009; 17:439-
447.

46. Nicolini A and Carpi A. Immune manipulation of advanced breast cancer: an interpretative model of the relationship between immune system and tumor cell biology. Medicinal research reviews. 2009; 29:436-471.

47. Szajnik M, Czystowska M, Szczepanski MJ, Mandapathil $\mathrm{M}$ and Whiteside TL. Tumor-derived microvesicles induce, expand and up-regulate biological activities of human regulatory T cells (Treg). PloS one. 2010; 5:e11469.

48. Dituri F, Mazzocca A, Giannelli G and Antonaci S. PI3K functions in cancer progression, anticancer immunity and immune evasion by tumors. Clinical \& developmental immunology. 2011; 2011:947858.

49. Toso A, Revandkar A, Di Mitri D, Guccini I, Proietti M, Sarti M, Pinton S, Zhang J, Kalathur M, Civenni G, Jarrossay D, Montani E, Marini C, Garcia-Escudero R, Scanziani E, Grassi F, et al. Enhancing chemotherapy efficacy in Pten-deficient prostate tumors by activating the senescence-associated antitumor immunity. Cell Rep. 2014; 9:75-89.

50. Bishop JL, Sio A, Angeles A, Roberts ME, Azad AA, Chi KN and Zoubeidi A. PD-L1 is highly expressed in Enzalutamide resistant prostate cancer. Oncotarget. 2015; 6:234-242. doi: 10.18632/oncotarget.2703.

51. Shen JK, Cote GM, Choy E, Yang P, Harmon D, Schwab J, Nielsen GP, Chebib I, Ferrone S, Wang X, Wang Y, Mankin H, Hornicek FJ and Duan Z. Programmed cell death ligand 1 expression in osteosarcoma. Cancer Immunol Res. 2014; 2:690-698.

52. Schatton T, Murphy GF, Frank NY, Yamaura K, WaagaGasser AM, Gasser M, Zhan Q, Jordan S, Duncan LM, Weishaupt C, Fuhlbrigge RC, Kupper TS, Sayegh MH and Frank MH. Identification of cells initiating human melanomas. Nature. 2008; 451:345-349.

53. Schatton T, Schutte U, Frank NY, Zhan Q, Hoerning A, Robles SC, Zhou J, Hodi FS, Spagnoli GC, Murphy GF and Frank MH. Modulation of T-cell activation by malignant melanoma initiating cells. Cancer Res. 2010; 70:697-708.

54. Fujita Y, Yagishita S, Hagiwara K, Yoshioka Y, Kosaka N, Takeshita F, Fujiwara T, Tsuta K, Nokihara H, Tamura T, Asamura H, Kawaishi M, Kuwano K and Ochiya T. The clinical relevance of the miR-197/CKS1B/STAT3-mediated PD-L1 network in chemoresistant non-small-cell lung cancer. Mol Ther. 2015; 23:717-727.

55. Hamid O, Robert C, Daud A, Hodi FS, Hwu WJ, Kefford R, Wolchok JD, Hersey P, Joseph RW, Weber JS, Dronca R, Gangadhar TC, Patnaik A, Zarour H, Joshua AM, Gergich $\mathrm{K}$, et al. Safety and tumor responses with lambrolizumab (anti-PD-1) in melanoma. N Engl J Med. 2013; 369:134144.

56. Brahmer JR, Tykodi SS, Chow LQ, Hwu WJ, Topalian SL, Hwu P, Drake CG, Camacho LH, Kauh J, Odunsi K, Pitot HC, Hamid O, Bhatia S, Martins R, Eaton K, Chen S, et al. Safety and activity of anti-PD-L1 antibody in patients with 
advanced cancer. N Engl J Med. 2012; 366:2455-2465.

57. Brahmer JR, Drake CG, Wollner I, Powderly JD, Picus J, Sharfman WH, Stankevich E, Pons A, Salay TM, McMiller TL, Gilson MM, Wang C, Selby M, Taube JM, Anders R, Chen L, et al. Phase I study of single-agent anti-programmed death-1 (MDX-1106) in refractory solid tumors: safety, clinical activity, pharmacodynamics, and immunologic correlates. J Clin Oncol. 2010; 28:3167-3175.

58. Sharma P, Wagner K, Wolchok JD and Allison JP. Novel cancer immunotherapy agents with survival benefit: recent successes and next steps. Nat Rev Cancer. 2011; 11:805812.

59. Ansell SM, Lesokhin AM, Borrello I, Halwani A, Scott EC, Gutierrez M, Schuster SJ, Millenson MM, Cattry D, Freeman GJ, Rodig SJ, Chapuy B, Ligon AH, Zhu L, Grosso JF, Kim SY, et al. PD-1 blockade with nivolumab in relapsed or refractory Hodgkin's lymphoma. N Engl J Med. 2015; 372:311-319.

60. Ramakrishnan $\mathrm{R}$ and Gabrilovich DI. Mechanism of synergistic effect of chemotherapy and immunotherapy of cancer. Cancer Immunol Immunother. 2011; 60:419-423.

61. Vacchelli E, Senovilla L, Eggermont A, Fridman WH, Galon J, Zitvogel L, Kroemer G and Galluzzi L. Trial watch: Chemotherapy with immunogenic cell death inducers. Oncoimmunology. 2013; 2:e23510.

62. Tang X, Li Q, Zhu Y, Zheng D, Dai J, Ni W, Wei J, Xue Y, Chen K, Hou W, Zhang C, Feng X and Liang Y. The advantages of PD1 activating chimeric receptor (PD1ACR) engineered lymphocytes for PDL1(+) cancer therapy. American journal of translational research. 2015; 7:460473.

63. Haile ST, Dalal SP, Clements V, Tamada K and Ostrand-
Rosenberg S. Soluble CD80 restores T cell activation and overcomes tumor cell programmed death ligand 1-mediated immune suppression. J Immunol. 2013; 191:2829-2836.

64. Qiu H, Liu S, Xie C, Long J and Feng Z. Regulating immunity and inhibiting tumor growth by the recombinant peptide sPD-1-CH50. Anticancer research. 2009; 29:50895094.

65. Borkner L, Kaiser A, van de Kasteele W, Andreesen R, Mackensen A, Haanen JB, Schumacher TN and Blank C. RNA interference targeting programmed death receptor-1 improves immune functions of tumor-specific $\mathrm{T}$ cells. Cancer immunology, immunotherapy. 2010; 59:1173-1183.

66. Armand P, Nagler A, Weller EA, Devine SM, Avigan DE, Chen YB, Kaminski MS, Holland HK, Winter JN, Mason JR, Fay JW, Rizzieri DA, Hosing CM, Ball ED, Uberti JP, Lazarus HM, et al. Disabling immune tolerance by programmed death-1 blockade with pidilizumab after autologous hematopoietic stem-cell transplantation for diffuse large B-cell lymphoma: results of an international phase II trial. J Clin Oncol. 2013; 31:4199-4206. 